\title{
FORENSIC TRAUMATIC CASES IN THE GERIATRIC POPULATION
}

Turkish Journal of Geriatrics

DOI: $10.31086 /$ tigeri.2020.135

2020; 23(1): 35-41

- Mustafa Talip ŞENER ${ }^{1}$

- Büşra BAYDEMIR KILINÇ ${ }^{1}$
CORRESPONDANCE

Mustafa TALIP ŞENER

Ataturk University Faculty of Medicine,

Department of Forensic Medicine, Erzurum,

TURKEY

Phone: +905057856861

e-mail: mustafatalipsener@gmail.com

Received: 11/11/2019

Accepted: 26/09/2020

${ }^{1}$ Ataturk University Faculty of Medicine,

Department of Forensic Medicine, Erzurum, TURKEY.

\section{Abstract}

Introduction: Physiological and metabolic changes arising in elderliness may increase the risk of trauma. The causes of trauma and trauma severity may vary with age. We aimed to determine the causes of trauma, traumatic lesions, and permanent damage status in the geriatric population by analyzing forensic trauma cases.

Materials and Method: Subjects were randomly selected from patients aged $\geq 65$ years whose forensic evaluation was performed at the department of forensic medicine. The sample size was determined with Epi-Info version 7 software. SPSS Windows 20.0 software was used to analyze the data.

Results: Of the patients, $68.9 \%$ were male and $31.1 \%$ were female, with a mean age of $72.8 \pm 6.11$ years. Among them, $53.8 \%$ and $46.2 \%$ were exposed to trauma due to non-accidental causes and an accident, respectively. Such accidental injuries most commonly occurred due to traffic accidents (78\%) and falls (16.7\%), whereas non-accidental injuries most commonly occurred due to intentional injuries (96.1\%). Accidental and non-accidental injuries were most commonly seen in females and males, respectively. The injury severity score was higher for accidental injuries. Minor and major injuries were observed in $95.1 \%$ and $4.9 \%$ patients, respectively, according to the injury severity score. Of the major injuries, $42.9 \%$ were in the head and neck region.

Conclusion: According to our results, non-accidental traumas in the geriatric population are similar to those in other age groups, whereas injuries due to falls increase in the former with a decrease in physiological reserves. Trauma severity appears to be more severe in accidental injuries.

Keywords: Geriatrics; Forensic Sciences; Wounds and Injuries; Violence; Accidents, Traffic. 


\section{INTRODUCTION}

Physiological and metabolic changes occur in elder age. These changes increase the risk of trauma. Of those admitted to the emergency department because of trauma average $12 \%$ are $>65$ years ( 1 $3)$. At the same time, $25 \%-28 \%$ of deaths in individuals aged $\geq 65$ years are associated with trauma (4). The causes of trauma and trauma severity may vary with age. In the geriatric population, traumas such as pedestrian injuries due to traffic accidents and falls primarily occur in relation to a decrease in physiological reserves (5).

Studies evaluating forensic trauma cases in the geriatric population are relatively limited. The studies examining traumas in the geriatric population usually include data from single centres in secondary or tertiary care institutions. Furthermore, it is difficult to determine whether permanent disability develops in these cases because it requires a long follow-up period during the wound healing process. According to the Turkish Penal Code, medico-legal evaluations are made at the end of the wound healing process. All findings related to the traumas; to which the cases were exposed, are identified with medico-legal evaluation. The treatment of these cases has been completed in several different secondary or tertiary health care institutions, and the origin of the trauma (whether it was an accidental or non-accidental one) has been determined by the judicial authorities. Therefore, investigation of trauma cases in the geriatric population undergoing medico-legal evaluation may provide comprehensive information about the traumas of these cases. For these reasons, in this study, we retrospectively evaluated forensic trauma patients aged $\geq 65$ years; who were admitted to the department of forensic medicine and who had undergone a forensic medical evaluation. We aimed to determine the causes of trauma, traumatic lesions, trauma severity, and traumatic permanent damage status specific to forensic cases in the geriatric population.

\section{MATERIALS AND METHODS}

\section{Sample size}

The sample size was initially determined to be 260 with Epi-Info version 7 software at a confidence interval of $99 \%$ with an expected prevalence of $12 \%$. The sample size was determined as 286 cases found (6).

\section{Patient selection}

A total of 286 patients $\geq 65$ years old who had undergone medico-legal evaluation because of trauma were randomly selected. Their age, gender, cause of trauma, traumatic lesions, injury severity, and permanent disability status were analyzed by scanning the year 2018 and earlier records of the Forensic Medicine Department of the Ataturk University. The injury severity score (ISS) is an anatomical trauma scoring system that best demonstrates mortality and morbidity in the geriatric population (7). The distribution of trauma according to anatomical regions and trauma severity in the patients were evaluated according to the ISS (8). Traumatic lesions were analyzed in terms of forensic medicine according to the guideline for the forensic evaluation of wounding crimes defined in Turkish Criminal Law.

\section{Statistical analysis}

Following data collection, the data were recorded in Microsoft Excel 2010 and SPSS Windows 20.0 software was used for data analysis. The normality test of the data was carried out with skewness and kurtosis values. The z-score was obtained by dividing the skewness and kurtosis values by their standard errors (9). Further, the percentage, mean, and standard deviation values of the data were calculated. The chi-square test was used to analyze comparisons between the groups, and the student's t-test was used to analyze the paired comparisons. A p-value $<0.05$ was considered statistically significant.

This study was conducted in accordance with Good Clinical Practice guidelines and the princi- 
ples of the Declaration of Helsinki. Ethics committee approval was obtained for this study (Ethics No: 26.09.2019/09).

\section{RESULTS}

Of the patients analyzed in this study, 68.9\% ( $\mathrm{n}=$ 197) were male and $31.1 \%(n=89)$ were female. The oldest patient was 97 years old, and the mean age was $72.8 \pm 6.11$ years. Of the patients, $46.2 \%$ ( $n$ $=132$ ) were exposed to trauma due to an accident, whereas $53.8 \%(n=154)$ were exposed to trauma because of non-accidental causes. The causes of the patients' trauma are shown in Table 1.

When traumas caused by accidental and non-accidental causes were compared, it was found that the patients injured because of accidents were 2 years older than those injured because of non-accidental causes. Furthermore, accidental injuries were more common in females, whereas non-accidental injuries were more common in males ( $p$ $=0.002$ ). The ISS was found to be higher for accidental injuries $(p<0.001)$. At the same time, it was found that bone fractures were more common in accidental injuries $(p<0.001)$, and patients who were injured because of accidents were mostly treated as inpatients $(p<0.001)$. The variables of accidental and non-accidental injuries are shown in Table 2.

When traumatic lesions in the patients were examined according to anatomical region, they were found to be located in a single anatomical region in $95 \%(n=272)$ of cases and in multiple anatomic regions in $5 \%(n=14)$ of cases. Of the isolated injuries, $56 \%(n=152)$ were located in superficial regions of the cutaneous and subcutaneous tissue. Regarding the patients, 95.1\% ( $n=272)$ had minor injuries and $4.9 \%(n=14)$ had major injuries according to the ISS. The severity of the injuries determined according to the ISS are shown in Table 3 .

When the bone fractures were analyzed, it was found that $32.4 \%(n=46)$ of patients had lower extremity fractures, whereas $12 \%(n=17)$ had upper extremity fractures. The bone fractures detected in the patients are shown in Table 4.

According to the results of the forensic reports that evaluated to Turkish Panel Code 11\% ( $n=31)$ of the patients had a life-threatening injury [head

Table 1. Distribution of cases according to the causes of trauma.

\begin{tabular}{|l|l|r|}
\cline { 2 - 2 } \multicolumn{1}{c|}{} & \multicolumn{1}{c|}{ \% (n) } \\
\hline \multirow{5}{*}{ Accidental injury } & Traffic accident pedestrian & $16.8(48)$ \\
\cline { 2 - 3 } & Traffic accident-passenger & $19.2(55)$ \\
\cline { 2 - 3 } & Fall & $7.7(22)$ \\
\cline { 2 - 3 } & Industrial accident & $1.4(4)$ \\
\cline { 2 - 3 } & Injury-associated hypothermia & $0.4(1)$ \\
\cline { 2 - 3 } Non-accidental injury & Hot milk scald burns & $0.4(1)$ \\
\cline { 2 - 3 } & Hot water scald burns & $0.4(1)$ \\
\hline & Physical assault & $51.6(148)$ \\
\cline { 2 - 3 } & Firearm injury & $0.7(2)$ \\
\cline { 2 - 3 } & Stab wounds & $1.4(4)$ \\
\hline
\end{tabular}


Table 2. Evaluation of accidental with non-accidental injury.

\begin{tabular}{|c|c|c|c|c|}
\hline \multirow{2}{*}{ Variables } & & \multirow{2}{*}{ Accidental injury } & Non-accidental injury & p-value \\
\hline & & & $\%(n=132)$ & $\%(n=154)$ \\
\hline Age & Mean ( \pm sd) & $73.9( \pm 6.6)$ & $71.8( \pm 5.4)$ & 0.002 \\
\hline \multirow{2}{*}{ Gender } & Male & $41.1(81)$ & 58.9 (116) & \multirow{2}{*}{0.011} \\
\hline & Female & $57.3(51)$ & $42.7(38)$ & \\
\hline \multirow{3}{*}{ Trauma severity } & Mean ISS score $( \pm \mathrm{sd})$ & $6.6( \pm 7.3)$ & $2.29( \pm 4.4)$ & $<0.001$ \\
\hline & ISS 0-15 & $42.9(111)$ & $57.1(148)$ & \multirow{2}{*}{$<0.001$} \\
\hline & ISS $16<$ & $77.8(21)$ & $22.2(6)$ & \\
\hline \multirow{2}{*}{ Bone fracture } & No & 31.7 (59) & $68.3(127)$ & \multirow{2}{*}{$<0.001$} \\
\hline & Yes & $73(73)$ & $27(27)$ & \\
\hline \multirow{2}{*}{$\begin{array}{l}\text { The } \\
\text { hospitalization }\end{array}$} & No & $32.8(67)$ & $67.2(137)$ & \multirow{2}{*}{$<0.001$} \\
\hline & Yes & 79.3 (65) & 20.7 (17) & \\
\hline
\end{tabular}

Table 3. Localization and severity of traumatic injuries according to the ISS scor.

\begin{tabular}{|c|c|c|c|c|}
\hline & Location of trauma & $\begin{array}{l}\text { Mean the } \\
\text { ISS score }\end{array}$ & Minor trauma ${ }^{a}$ & Major trauma ${ }^{b}$ \\
\hline & & & $\%(n)$ & $\%(n)$ \\
\hline \multirow{6}{*}{ Isolated } & Head or neck & 16 & $3.1(9)$ & $2.1(6)$ \\
\hline & Face & 2.4 & $6.3(18)$ & \\
\hline & Thorax & 13 & $5.6(16)$ & \\
\hline & Abdominal or pelvic content & 9 & $0.3(1)$ & \\
\hline & Ekstremities or pelvic girdle & 5.7 & $19.2(55)$ & \\
\hline & Skin and the subcutaneous tissue & 1 & $57.3(167)$ & \\
\hline \multirow{10}{*}{ Multiple } & Head or neck, Face & & $0.7(2)$ & $0.3(1)$ \\
\hline & Face, Thorax & & $0.3(1)$ & $0.3(1)$ \\
\hline & Head or neck, Abdominal or pelvic content & & & $0.3(1)$ \\
\hline & Head or neck, Ekstremities or pelvic girdle & & & $0.3(1)$ \\
\hline & Thorax, Ekstremities or pelvic girdle & & & $0.3(1)$ \\
\hline & Face, Ekstremities or pelvic girdle & & $0.7(2)$ & \\
\hline & $\begin{array}{l}\text { Ekstremities or pelvic girdle, Skin and the } \\
\text { subcutaneous tissue }\end{array}$ & & $0.3(1)$ & \\
\hline & Face, Thorax, Ekstremities or pelvic girdle & & & $0.3(1)$ \\
\hline & $\begin{array}{l}\text { Head or neck, Face, Thorax, Ekstremities or pelvic } \\
\text { girdle }\end{array}$ & & & $0.7(2)$ \\
\hline & Total & & $95.1(272)$ & $4.9(14)$ \\
\hline
\end{tabular}

\footnotetext{
a: Cases with ISS score between 0-15, b: Cases with ISS score of 16 or higher (8).
} 
Table 4. . Distribution of the bone fractures detected in the cases.

\begin{tabular}{|l|r|}
\hline Facial bones & $29(20.4)$ \\
\hline Femur & $18(12.7)$ \\
\hline Tibia-fibula & $16(11.3)$ \\
\hline Ribs & $15(10.6)$ \\
\hline Cranium & $13(9.2)$ \\
\hline Radius-ulna & $11(7.8)$ \\
\hline Vertebral colon & $10(7)$ \\
\hline Foot-ankle & $10(7)$ \\
\hline Pelvis & $5(3.5)$ \\
\hline Clavicle & $5(3.5)$ \\
\hline Hand-wrist & $4(2.8)$ \\
\hline Humerus & $2(1.4)$ \\
\hline Scapula & $2(1.4)$ \\
\hline Patella & $2(1.4)$ \\
\hline Total ${ }^{a}$ & $142(100)$ \\
\hline
\end{tabular}

a: Some cases have more than one fracture. Therefore, the number of fractures is higher than the number of cases.

and neck region $(n=19)$, thoracic region $(n=11)$ and abdomen region $(n=1)]$. From the forensic aspect, $9.5 \%(n=29)$ of all patients and $26 \%(n=26)$ of those with a bone fracture were found to have permanent damage. Of all the cases of permanent damage, $80 \%(n=23), 10 \%(n=3), 7 \%(n=2)$, and $3 \%(n=1)$ were developed because of limited range of motion, craniectomy defects, paraplegia, and loss of vision, respectively. It was found that permanent damage was primarily caused by accidental injuries and fractures of the long bones of the extremities $(p<0.001)$.

\section{DISCUSSION}

As the age increases, geriatric individuals experience a decrease in perception and attention, mental and motor activity, sensory functions such as vision and hearing, and postural structure impair- ment. These pathophysiological changes cause elderly individuals to become exposed to more trauma (5). Although the female population is higher in the geriatric age group, the incidence of trauma is higher in males $(10,11)$. In the present study analyzing forensic trauma cases in the geriatric population, the number of male patients was found to be higher. More exposure to trauma in males may be associated with a more active social life. In addition, another factor that increases the risk of exposure to trauma in the geriatric population is increased opportunities for active living $(12,13)$.

Traffic accidents and falls are the most common causes of accidental trauma in the geriatric population, and pedestrian injured due to traffic accidents are more commonly seen in the this population (14-17). In our study, traffic accidents were the most common cause of injury because of accidents, and the number of patients facing pedestrian injured due to traffic accidents was slightly higher. Among the accidental injuries, the second most common cause was found to be falls. Falls and domestic accidents are considered indicators of balance disorders, visual problems, and other neurological problems in the geriatric age group (18). The frequency of traffic accidents and falls increases in the geriatric age group (15-17). Other accidental injuries identified in our study such as occupational accidents, hot water scald burns, and milk scald burns were also determined to be traumas associated with physiological disabilities. In our study, it was found that the patients injured because of accidents were 2 years older than those injured because of non-accidental causes. Accordingly, we can speculate that traumatic injuries due to accidents increase with age.

The other group, consisting of $53.8 \%$ of the patients, had faced non-accidental injuries. In studies investigating forensic medical evaluation cases, it can been seen that non-accidental injuries such as physical assault, sharp object injuries, and gunshot injuries account for approximately half of the traumas in all age groups $(11,19)$. In the geriatric 
population, physical assault seems to be the most common cause of non-accidental trauma.

According to the ISS anatomical trauma scoring system, $95.1 \%$ of the patients had minor traumas primarily located in superficial regions of the cutaneous and subcutaneous tissues. Although the number of major injuries was low, they were most commonly located in the head and neck region. In line with the literature, minor traumas were mostly detected in cases of physical assault, whereas major traumas were mostly identified in traffic accidents (18). Traffic accidents result in high-energy traumas, leading to more bone fractures, more major trauma, and more inpatient treatment of patients. Although the number of minor traumas is higher, minor traumas due to increased comorbidity in the elderly may result in more serious consequences and higher rates of mortality and morbidity (20-22). In geriatric traumas, the most important cause of death is head trauma (23). In our study, major injuries were most commonly located in the head and neck region, and, from the forensic aspect, the majority of life-threatening injuries were also identified in this region.

Traumas are one of the major causes of permanent damage development in the musculoskeletal system (24). It has been stated that the rate of anatomic loss or functional impairment arising in elderly individuals because of traumatic causes varies between $25 \%$ and $47 \%$, and these patients cannot return to their pre-event conditions (25). In our study, we found permanent damage in $9.5 \%$ of the geriatric population according to forensic medical evaluation. A significant portion of the

\section{REFERENCES}

1. Gulacti U, Lok U, Celik M, Aktas N, Polat H. The ED use and non-urgent visits of elderly patients. Turk J Emerg Med 2016;16(4):141-5. (PMID: 27995205).

2. Ross MA, Compton S, Richardson D, Jones R, Nittis T, Wilson A. The use and effectiveness of an emergency department observation unit for elderly patients. Ann permanent injuries was a limited range of motion due to extremity and pelvic bone fractures. The rates of permanent damage that we determined in the patients with bone fractures were similar to those in the literature (11). According to forensic medical evaluation, an organ or extremity identified as traumatized should have lost at least $10 \%$ of its anatomic structure and/or function to be considered permanently damaged. With increasing comorbidity in the geriatric population, nearly complete recovery may not be possible, especially in skeletal system fractures. Therefore, the rate of permanent damage in the geriatric population may be even higher when patients with less anatomic loss or functional impairment are included.

In conclusion, according to our results, the most common cause of non-accidental trauma in the geriatric population is physical assault, which has a similar rate in all age groups. Furthermore, pedestrian injured due to traffic accidents and fall-related traumas are the major causes of accidental injuries in the geriatric population. Sensory, perceptual, and physical disabilities developing with increasing age make older individuals more vulnerable to environmental dangers. With increasing comorbidity, traumas may result in more severe consequences. Measures taken for the living space and in consideration of the physiological disability of the geriatric population can reduce the rates of accidental traumas and disabilities.

\section{CONFLICT OF INTEREST}

The authors declare that they have no conflict of interest.

3. Vanpee D, Swine C, Vandenbossche P, Gillet JB. Epidemiological profile of geriatric patients admitted to the emergency department of a university hospital localized in a rural area. Eur J Emerg Med 2001;8(4):301-4. (PMID:11785598). 
4. OJ Ma, SW Meldon. Geriatric Trauma. In:Tintinalli JE, Kelen GD, Stapczynski JS (Eds). Emergency Medicine A Comprehensive Study Guide. 6th edition, McGrawHill, New York 2004, pp 1549-53.

5. Miller KE, Zylstra RG, Standridge JB. The geriatric patient: a systematic approach to maintaining health. American Family Physician 2000;61(49):1089-104. (PMID:10706161).

6. Fahim NK, Negida A, Fahim AK. Sample size calculation guide-part 3: how to calculate the sample size for an independent case-control study. Adv J Emerg Med 2019;3(2):20. (PMID:31172131).

7. Clement ND, Tennant C, Muwanga C. Polytrauma in the elderly: predictors of the cause and time of death. Scand J Trauma Resusc Emerg Med 2010;18(1):26. (PMID:20465806).

8. Goris RJA. The injury severity score. World Surg 1983;7(1):12-8. (PMID:6837052).

9. Kim HY. Statistical notes for clinical researchers: assessing normal distribution (2) using skewness and kurtosis. Restor Dent Endod. 2013;38(1):52-4. (PMID:23495371).

10. Magnotti LJ, Fischer PE, Zarzaur BL, Fabian TC, Croce MA. Impact of gender on outcomes after blunt injury: a definitive analysis of more than 36,000 trauma patients. J Am Coll Surg 2008;206(5):984-91. (PMID:18471739)

11. Karbeyaz K, Gunduz T, Balci Y. Forensic medicine approach to bone fractures in the framework of the new Turkish penal code. Turkish Journal of Trauma and Emergency Surgery 2010;16(5):453-8. (PMID: 21038125).

12. Mann NC, Cahn RM, Mullins RJ, Brand DM, Jurkovich GJ. Survival among injured geriatric patients during construction of a statewide trauma system. J Trauma 2001;50(6):1111-6. (PMID:11426127).

13. Hung KKC, Yeung JH, Cheung CS, et al. Trauma team activation criteria and outcomes of geriatric trauma: 10 year single centre cohort study. Am J Emerg Med 2019;37(3):450-6. (PMID:30041911).

14. Eom KS. Epidemiology and outcomes of traumatic brain injury in elderly population: a multicenter analysis using Korean Neuro-Trauma Data Bank System 20102014. J Korean Neurosurg Soc 2019;62(2):243-55. (PMID:30840980).
15. Peter RM, Joseph A, John KR, Logaraj M. A community-based case-control study on the risk of fall among the elderly in rural Kattankulathur block, Tamil Nadu. Indian J Community Med 2019;44(3):27780. (PMID:31602119)

16. Greene WR, Smith R. Driving in the geriatric population. Clin Geriatr Med 2019;35(1):127-31. (PMID:30390978).

17. Fraade-Blanar LA, Ebel BE, Larson EB, et al. Cognitive decline and older driver crash risk. J Am Geriatr Soc 2018;66(6):1075-81. (PMID:29667168)

18. Kandis $H$, Karakus A, Katirci $Y$, Karapolat $S$, Kara $I H$. Geriatric population and forensic traumas. Turkish Journal of Geriatrics 2011;14(3):193-8.

19. Akbaba M, Baransel Isır A, Karaarslan B, Dulger HE. Evaluation of the forensic reports documented at the Department of Forensic Medicine of Gaziantep University (2005-2011). The Bulletin of Legal Medicine 2012;17(2):10-18.

20. Bilgin N. MertE. The characteristics of geriatric forensic cases. Turkish Journal of Geriatrics 2005;8(1):13-6.

21. Hruska K, Ruge T. The tragically hip trauma in elderly patients. Emerg Med Clin North Am 2018;36(1):219235. (PMID:29132579).

22. Gioffre-Florio M, Murabito LM, Visalli C, Pergolizzi FP, Fama F. Trauma in elderly patients: a study of prevalence, comorbidities and gender differences. G Chir 2018;39(1):35-40. (PMID:29549679).

23. Akkose Aydın S, Bulut M, Fedakar R, Ozgurer A, Ozdemir F. Trauma in the elderly patients in Bursa. Turkish Journal of Trauma and Emergency Surgery 2006;12(3):230-4. (PMID: 16850362).

24. Kocak FA, Kurt EE, Sas S, et al. Disability distribution of geriatric patients applying to the board of health for disabled in a rural region. Turk $\mathrm{J}$ Osteoporos 2018;24:92-9.

25. Ozdogan M, Agalar F, Daphan CE. Factors effecting mortality and morbiditiy in the trauma in the elderly. Turkish Journal of Trauma and Emergency Surgery 1999;5(3):189-93. 